\title{
PLAN DE MANEJO DEL PATRIMONIO CULTURAL EN MÉXICO: LA EXPERIENCIA DEL CENTRO HISTÓRICO DE OAXACA DE JUÁREZ ${ }^{[*]}$
}

\section{PLAN FOR THE MANAGEMENT OF CULTURAL HERITAGE IN MEXICO: THE EXPERIENCE OF THE HISTORICAL CENTER OF OAXACA DE JUÁREZ}

\author{
KARINA JANETH GUTIÉRREZ CHIRA ${ }^{(\star *)}$ \\ (iD) https://orcid.org/0000-0001-9849-4018 \\ karito_janeth@hotmail.com \\ Universidad Nacional de Ingeniería (Perú)
}

Fecha de recepción: 30 de abril de 2019

Fecha de aprobación: 16 de julio de 2019

\section{RESUMEN}

El Centro Histórico de Oaxaca de Juárez es uno de los diez centros históricos mexicanos inscritos por la Unesco como Patrimonio de la Humanidad. Es a partir de esta inscripción que se generó un mayor interés por el manejo, la conservación y difusión de las riquezas culturales de esta zona, por lo que se elaboró el Plan Parcial de Conservación del Centro Histórico de Oaxaca de Juárez de 1997, planteado como un instrumento participativo y concertado, que muestra las problemáticas de la época y plantea algunas estrategias como solución. Sin embargo, los objetivos de este plan no fueron cumplidos a cabalidad. Hoy en día, se presentan nuevos retos a afrontar en el Centro Histórico de Oaxaca de Juárez, lo que manifiesta la necesidad de una actualización del plan o la creación de otros instrumentos de manejo y ordenamiento de su centro. Es necesario aprender de esta experiencia para poder hacer puntos de comparación con los diversos tipos de centros históricos que existen en América Latina.

\section{PALABRAS CLAVE}

Centro Histórico; Oaxaca de Juárez; México

\begin{abstract}
The Historic Center of Oaxaca de Juárez is one of the ten historic Mexican centers inscribed by Unesco as World Heritage Sites. Due to this inscription, a greater interest in the management, conservation and diffusion of the cultural wealth of this area has been generated, which is why the Partial Plan of Conservation of the Historic Center of Oaxaca de Juarez of 1997 was elaborated and proposed as a participatory and concerted instrument that shows the problems of the time and offers some strategies as a solution. However, the objectives of this plan were not fully completed. Today, there are new challenges to face in the historic center of Oaxaca de Juarez that manifest the need for an update of the plan or the creation of other management and ordering tools for its center. It is necessary to learn from this experience to be able to make points of comparison with the various types of historic centers that exist in Latin America.
\end{abstract}

\section{KEYWORDS}

Historic center; Oaxaca de Juárez; México

(*) Este artículo fue elaborado como parte del trabajo de investigación titulado Plan de manejo del patrimonio cultural en México: la experiencia del centro histórico de Oaxaca de Juárez, desarrollado en el curso Taller de Intervención en Áreas, Conjuntos y Centros Históricos dictado por el arquitecto Dr. José Hayakawa Casas (ciclo 2018-2) en la Maestría de Conservación y Gestión de Patrimonio Edificado de la Unidad de Posgrado de la Facultad de Arquitectura, Urbanismo y Artes de la Universidad Nacional de Ingeniería (UNI).

(**) Bachiller por la Facultad de Arquitectura de la Universidad Peruana de Ciencias Aplicadas (UPC). Ha participado en los proyectos de restauración de la Catedral de Lima, el Convento las Mercedarias, la Casona El Estadio, entre otras. Actualmente es alumna de la Maestría de Conservación y Gestión de Patrimonio Edificado de la Unidad de Posgrado de la Facultad de Arquitectura, Urbanismo y Artes de la UNI. 
devenir Vol. 6, N¹2, JULIO - DICIEMBRE 2019, PP. 67-84 - EstudIOS I ISSN 2312-7562 | E-ISSN 2616-4949

UNIVERSIDAD NACIONAL DE INGENIERÍA, LIMA

doi: https://doi.org/10.21754/devenir.v6i12.744

\section{México y sus diversos perfiles}

\section{Antecedentes}

La república de México, llamada oficialmente Estados Unidos Mexicanos, es el decimotercer país más extenso del mundo y el tercero más grande de América Latina con una extensión de $1964375 \mathrm{~km}$. Cuenta con una población estimada en más de 124 miIlones (Instituto Nacional de Estadística y Geografía, 2017, p. 46) y, en lo particular, su economía está basada en el mercado de libre comercio, regulada por los tratados de libre comercio siendo el más influyente el Tratado de Libre Comercio de América del Norte (TLCAN o NAFTA por sus siglas en inglés) con los Gobiernos de Estados Unidos y Canadá. En el año 2006, el comercio de México con los norteamericanos representaba cerca del $90 \%$ de sus exportaciones y el $55 \%$ de sus importaciones.

Históricamente, en el territorio se desarrollaron diversas civilizaciones; una de ellas fueron los grupos de la filiación zapoteca que se ubicaron en la zona sureste del país, exactamente en el territorio del estado de Oaxaca (400 a. C. y 1000 d. C.) y que marcarían la identidad que tiene hasta la actualidad. Posteriormente, con la conquista española se estableció el virreinato de Nueva España en el territorio mexicano (1535) y el 28 de setiembre de 1821 se declaró la independencia y se estableció la república mexicana. Sin embargo, ello trajo consigo inestabilidad política (cuarenta gobiernos en treinta años debido a las disputas entre los liberales y conservadores). La llegada del gobierno del presidente Porfirio Díaz (1877-1911) marcó un hito en la historia, ya que a partir de las rebeliones en contra de su gobierno dictatorial es que nació la denominada Revolución mexicana, período que se caracterizó por la promulgación de documentos importantes, entre ellos la Constitución de 1917 (ver Figuras 1, 2 y 3).

México está establecido como una república representativa, democrática y federal. En conjunto, está conformado por una federación de estados regidos por las leyes de la Constitución Política de 1917, mencionada anteriormente. Está dividido políticamente en 32 entidades federativas, de las cuales: (a) 31 son estados libres y soberanos, es decir, tienen su propio gobierno y leyes, además de un territorio y población definida. También presentan su propia constitución, aunque esta no puede contraponerse a la Constitución de la República. Cada estado tiene su capital y está dividido internamente en municipios, gobernados cada uno por un respectivo ayuntamiento, del cual es responsable el presidente municipal y los representantes del cabildo elegidos por la población correspondiente, y (b) 1 distrito federal donde residen los poderes federales.

\section{Cultura en México}

\section{Organizaciones culturales y leyes}

Es a partir de la promulgación de la Constitución de 1917 que en México despertó un sentimiento nacionalista. El tema de la cultura apareció por primera vez en el artículo $3^{\circ}$ de dicha Constitución:

El criterio que orientará la educación se basará en el progreso científico, luchará contra la ignorancia y sus efectos, la servidumbre, los fanatismos y los perjuicios. Además:

a) Será democrático considerando a la democracia no solamente como una estructura jurídica y un régimen político, sino como un sistema de vida fundado en el constante mejoramiento económico, social y cultural del pueblo.

b) Será nacional, en cuanto — sin hostilidad ni exclusividad- atenderá la comprensión de nuestros problemas al aprovechamiento de nuestros recursos, a la defensa de nuestra independencia política, al aseguramiento de nuestra independencia económica y a la continuidad 


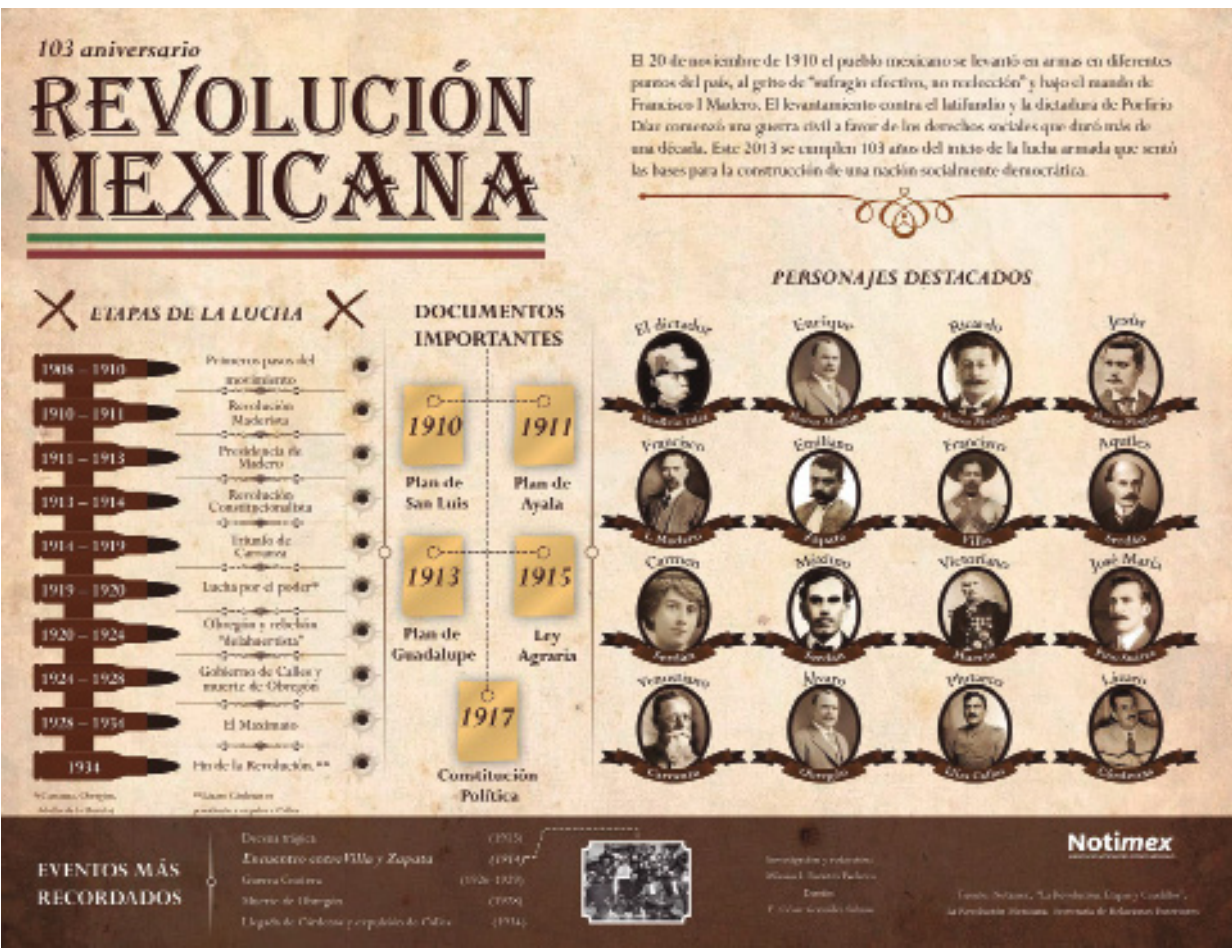

Figura 1. Revolución: etapas y caudillos. Infografía de Notimex (Agencia de noticias del Estado de México), 2019

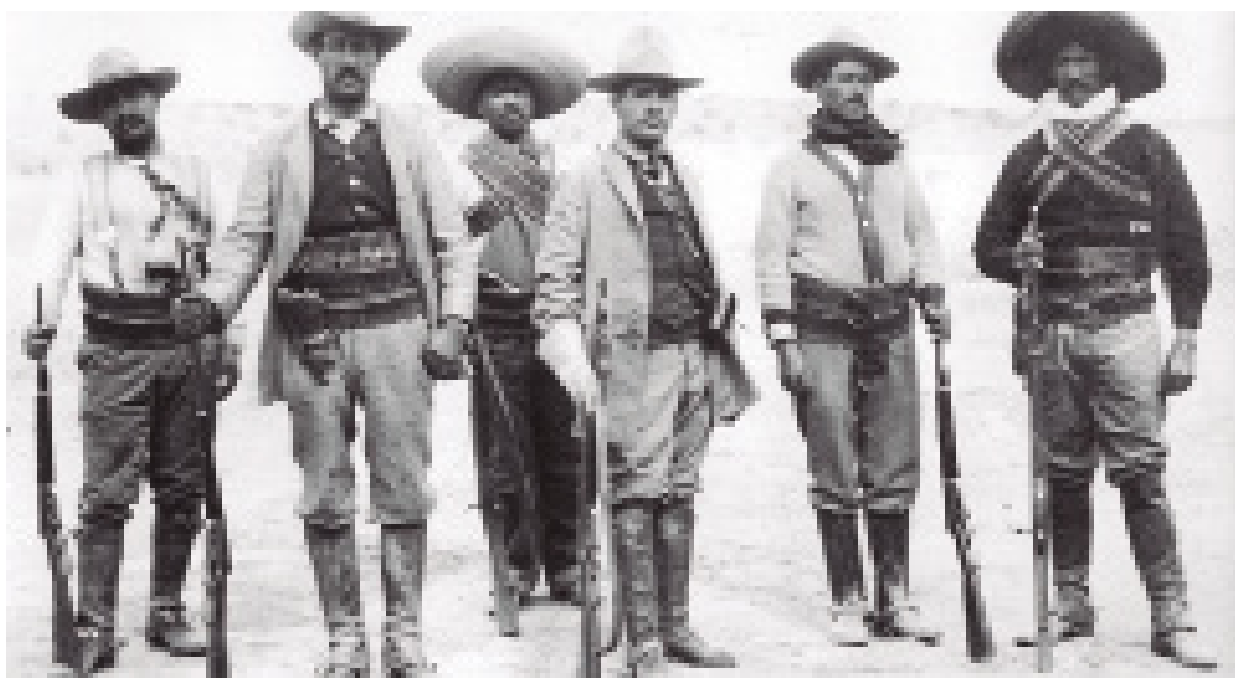

Figura2. Revoluciónmexicana. Recuperado dehttps://mundo.sputniknews.com/firmas/201608131062799792-fotos-mexico-revolucion/

y acercamiento a nuestra cultura. (Cámara de Diputados del Honorable Congreso de la Unión, 2018, párr. 6)

Por lo tanto, el discurso nacionalista y de cultura iban de la mano (Cámara de Diputados del Honorable Congreso de la Unión, 2018). Uno de los primeros pasos que formularon las primeras propuestas de políticas culturales fue la creación, para la década de 1920, de (a) la Secretaría de la República (1921); para la década de 1930, (a) el Fondo de Cultura Económica (1934) y (b) el Instituto Nacional de Antropología e Historia (INAH) 


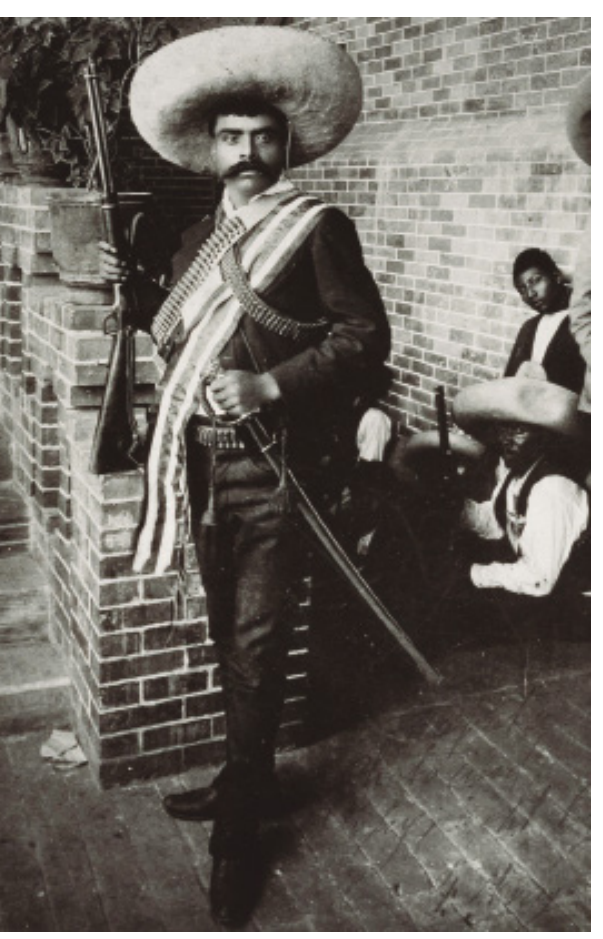

Figura 3. Emiliano Zapata: Revolución mexicana. Recuperado de http:// neomexicanismos.com/cultura-mexico/revolucion-mexicana-datos-curiosos-resena-historica-consecuencias/
(1939); para la década de 1940, (a) la Secretaría de Cultura de México (1942), (b) el Instituto Nacional de Bellas Artes (INBA, 1946) y (c) el Instituto Nacional Indigenista (1948).

Para la década de 1950, paulatinamente el nacionalismo se fue convirtiendo en una búsqueda de la modernización. De esta manera, México inició su inserción en los ámbitos internacionales a nivel cultural. Debido a ello, se crearon, para la década de 1980, (a) El Consejo Nacional para la Cultura y las Artes (Conaculta), el cual se convirtió en el organismo rector de la cultura en México, pero a su vez le quitó autonomía al INAH y al INBA, y (b) El Fondo Nacional para las Culturas y las Artes (Fonca), destinado a «fomentar y estimular la creación artística» que superpuso algunas de las funciones del INBA.

A nivel federal, el INAH es la institución más importante encargada del patrimonio histórico y arqueológico, para lo cual cuenta con centros de formación y cuadros profesionales especializados. Su labor es normativa, asesora y supervisora. El instituto cuenta con centros en cada estado y recursos propios, los cuales no alcanzan para restaurar todo el patrimonio, por lo cual opera con recursos provenientes de otras fuentes. Existen cuerpos colegiados para revisar y recomendar al INAH las acciones a tomar en casos difíciles o técnicamente complejos. Asimismo, el INAH ha intervenido directa o indirectamente en la elaboración de planes o programas parciales de conservación de centros históricos y tiene a su cargo el seguimiento de las convenciones (Sepúlveda, 2017).

Por otro lado, las leyes más importantes promulgadas en cuanto a cultura fueron las siguientes: para la década de 1960, (a) Ley General de Bienes Nacionales (1969), que declara de dominio de la nación a distintos bienes culturales (monumentos arqueológicos, artísticos e históricos, manuscritos, libros, entre otros); para la década de 1970, (a) Ley Federal del Patrimonio Cultural de la Nación (1970) y (b) Ley Federal sobre Monumentos y Zonas Arqueológicas, Artísticos e Históricos (1972). Cabe señalar que la Ley Federal sobre Monumentos y Zonas Arqueológicas, Artísticos e Históricos (1972), vigente en la actualidad, no explica de manera específica el uso de suelo. La Secretaría de Desarrollo Social (Sedesol) manifiesta que es necesario que esta ley defina mejor lo que se considera como «zona de monumentos», incluso que defina "zona de monumentos artísticos». Una vez especificados los conceptos, las condiciones a las que se sujeten las construcciones deben ser de carácter obligatorio (no son obligatorias y nunca se han incluido en las declaratorias de zonas de monumentos históricos).

\section{Urbanismo}

Después de la Revolución mexicana, la población mexicana comenzó a crecer de una manera descontrolada debido al proceso de industrialización, ya que la acción del Estado estaba dirigida a promover la inversión para la creación de la infraestructura soporte de esta industrialización, lo cual provocó la concentración de población y recursos en la Ciudad de México (Alarcón, 2018, p. 119). Por lo tanto, como resultado de la toma de conciencia por la magnitud de la problemática, se promulgaron las siguientes leyes para la década de 1970: (a) La Ley de Desarrollo Urbano del Distrito Federal (1975), que buscaba regular el crecimiento en relación a un nuevo orden urbano, para lo cual fue elaborado el Plan Director de Desarrollo Urbano del Distrito Federal; (b) Ley General de Asentamientos Humanos (LGAH) (1976), que en el 2016 fue actualizada como Ley General de Asentamientos Humanos, Ordenamiento Territorial y Desarrollo Urbano. Sin embargo, esta ley que fue actualizada en el 2016 no incorpora los conceptos de «centro histórico» o «paisaje urbano histórico», y mantiene nociones amplias como «patrimonio cultural natural»e «imagen urbana». Declara que los planes y programas para la protección de los centros históricos son responsabilidad del municipio correspondiente. En este sentido, no integra el desarrollo urbano con la preservación de patrimonio cultural (Sepúlveda, 2017, p. 8). En cuanto a instituciones, se creó la Secretaría de Asentamientos Humanos y Obras Públicas (Sahop) como ministerio especializado que, además, se ocupaba de la planeación de los centros de población, de la ecología urbana, del equipamiento, el suelo y la vivienda. 


\section{Centros históricos de México}

\section{Evolución y programas para centros históricos}

Las definiciones de "centro histórico» han evolucionado a través del tiempo; sin embargo, cabe señalar algunas de ellas, como las que plantea Fernando Carrión al referirse al centro histórico como «una relación social compleja y particular donde los sujetos patrimoniales definen el ámbito específico de la conflictividad (la heredad) y el mecanismo de transferencia generacional (sustentabilidad). El traspaso social del testimonio se desarrolla en el marco de un conflicto que debe incrementar valor en el proceso de transmisión» (Carrión, 2000, p. 12). También cabe mencionar la definición formulada en el Coloquio sobre Preservación de los Centros Históricos ante el Crecimiento de las Ciudades Contemporáneas, en donde «los centros históricos son todos aquellos asentamientos humanos vivos, fuertemente condicionados por una estructura física proveniente del pasado, reconocibles como representativos de la evolución de un pueblo» (Hayakawa, 2015, p. 210). En esta misma línea, Leonardo Benévolo reconoce al centro histórico como «un organismo unitario constituido por un ambiente natural, físico y un cuerpo social integrados entre sí» (citado en Hayakawa, 2015, p. 211).

Por otro lado, debemos destacar los conceptos que plantea el Programa Regional de Patrimonio Cultural de la Unesco (PNUD-Unesco) donde se considera a los centros históricos como lo siguiente:

a) áreas sociales, o sea como lugares de vida y trabajo, b) áreas económicas, o sea con espacios como actividades formales e informales, vinculadas a la ciudad y a la región, c) áreas culturales, o sea, testimonios de la historia social que contribuyen a la identidad cultural del país y de sus habitantes, d) áreas urbanísticas, con ejemplos arquitectónicos, espacios urbanos y usos del suelo que reflejen formas de vida y aportes estéticos del pasado parcialmente modificados por el proceso socioeconómico y de urbanización contemporáneos, e) un medio ambiente sujeto a la presión de ciclos cambiantes en la historia de la ciudad y de la región. (Hayakawa, 2015, p. 212)

La importancia de estos conceptos, que tomaremos en cuenta, radica en una aproximación planteada no a partir del monumento o ambientes urbanos monumentales, sino a partir de la función de los residentes. Estos conceptos de centro histórico reconocen a la comunidad como el actor principal de los centros.

En México, las primeras valoraciones de los centros históricos corresponden a las ordenanzas de Felipe II (1573), en las cuales se considera a los centros como espacios de conjunción entre la cultura local y los modelos españoles. Estas ordenanzas señalaban que «había que comenzar con la delimitación de la plaza principal, o plaza mayor, y a partir de allí construir la red de calles» (Alarcón, 2018, p. 22). Después de declarada la independencia (1821), surgió el sentimiento nacionalista conducido por «mestizos», lo cual generó interés por los elementos culturales propios. Es en ese momento que comenzó una gran producción de leyes, reglamentos, decretos, entre otros, acerca de la riqueza cultural de México, que se formalizó oficialmente con su inclusión en las leyes culturales, con la creación del INAH (ya antes mencionada) y la Secretaría de Bienes Nacionales. Posteriormente, en 1984 se firmó la Convención del Patrimonio Mundial, lo que obligó al país a implementar planes de manejo y programas especiales para las intervenciones en los centros históricos. En la actualidad, México cuenta con 31 sitios inscritos, entre ellos 10 centros históricos: Ciudad de México, Puebla, Oaxaca, Morelia, Querétaro, Campeche, Zacatecas, San Miguel de Allende, Tlacotalpan y Guanajuato.

En cuanto a programas para centros históricos, la Sedesol juega un papel muy importante, ya que sus acciones están destinadas a colaborar con la elaboración de planes de manejo. Cabe señalar que, para el 2010, Sedesol elaboró una Guía Metodológica para la Formulación, Seguimiento y Evaluación de los Planes de Manejo para las Ciu- 
dades Mexicanas Patrimonio de la Humanidad y los Centros Históricos y Tradicionales del País. Los aportes principales de esta guía fueron dos: (a) una propuesta de la elaboración de los planes de manejo según las variantes locales (variantes no antes vistas, ya que se elaboraba el mismo plan para todos los centros históricos) y (b) los planes de manejo deben ir de la mano con las políticas urbanas de la zona (los planes de desarrollo urbano aparecían por primera vez en la implementación de estos programas). Asimismo, el INAH elaboró un Programa de Trabajo 2007-2012 para fortalecer el «modelo metodológico, la instrumentación de procesos de planeación y la consecuente institucionalización de Planes de Manejo» (Alarcón, 2018, p. 120).

\section{Financiamiento}

En cuanto a las alternativas para el financiamiento de los centros históricos, tenemos a los recursos fiscales que se dan a través de los impuestos locales y a los impuestos directos de los beneficiarios directos de una obra pública. Asimismo, se cuenta con instrumentos de fomento para el financiamiento como los incentivos locales, las facilidades administrativas, el sistema de transferencias de derechos (cuando un inmueble con valor patrimonial «vende» sus derechos de construcción a un inmueble, sea este existente o de obra nueva, ubicado en otra zona de la ciudad, en donde permite al vendedor obtener recursos para su mejora y mantenimiento) y los subsidios (Frutos, 2008). Las entidades e instituciones que participan en la inversión son las siguientes:

- La Sedesol, con su programa Hábitat-Vertiente de los Centros Históricos

- El Fonca (ya antes mencionado)

- La Secretaría de Turismo (Sectur), con el programa de Fondo Mixto de las Ciudades Coloniales

- Gobiernos estatales y locales

Aquí, la Sedesol, a través de la Dirección General de Desarrollo Urbano, creó el Programa Hábitat. Este programa presenta dos vertientes. La segunda vertiente es la de Centros Históricos:

El programa Hábitat, como una herramienta gubernamental dirigida por la Sedesol, articula los objetivos de la política social con los de la política de desarrollo urbano y ordenamiento territorial del Gobierno Federal, para contribuir a reducir la pobreza urbana y mejorar la calidad de vida de los habitantes de las zonas urbanas marginadas. Los subsidios de la Vertiente Centros Históricos se asignarán por partes iguales entre las ciudades con sitios y centros históricos inscritos en la Lista del Patrimonio Mundial de la UNESCO. Estos recursos se utilizarán exclusivamente en obras o acciones para la protección, conservación y revitalización de estos Centros y se aplicarán únicamente dentro del ámbito territorial reconocido como Centro Histórico y en sus accesos viales, de acuerdo con las delimitaciones establecidas por las declaratorias expedidas por la Unesco y en los accesos viales que sean autorizados por la Sedesol. (Secretaría de Gobernación, 2011, p. 6)

Esta vertiente asigna únicamente el $1.9 \%$ de sus recursos, monto insuficiente, por lo que se necesita necesariamente apoyos del INAH e INBA. El programa implementó subsidios a través de los mismos municipios, cubiertos en $70 \%$ por el Gobierno federal y en $30 \%$ por el Gobierno municipal, los cuales son asignados anualmente a cada uno de los 10 centros históricos declarados Patrimonio de la Humanidad en México. Otra institución que se suma es la Asociación Nacional de Ciudades Mexicanas del Patrimonio Mundial (1996), la cual busca gestionar recursos, generar alianzas y garantizar la continuidad en la aplicación de políticas públicas en torno al rescate de los centros históricos, y está conformada por los presidentes municipales de las ciudades mexicanas patrimonio mundial (Portal Iberoamericano de Gestión Cultural, s. f.). 


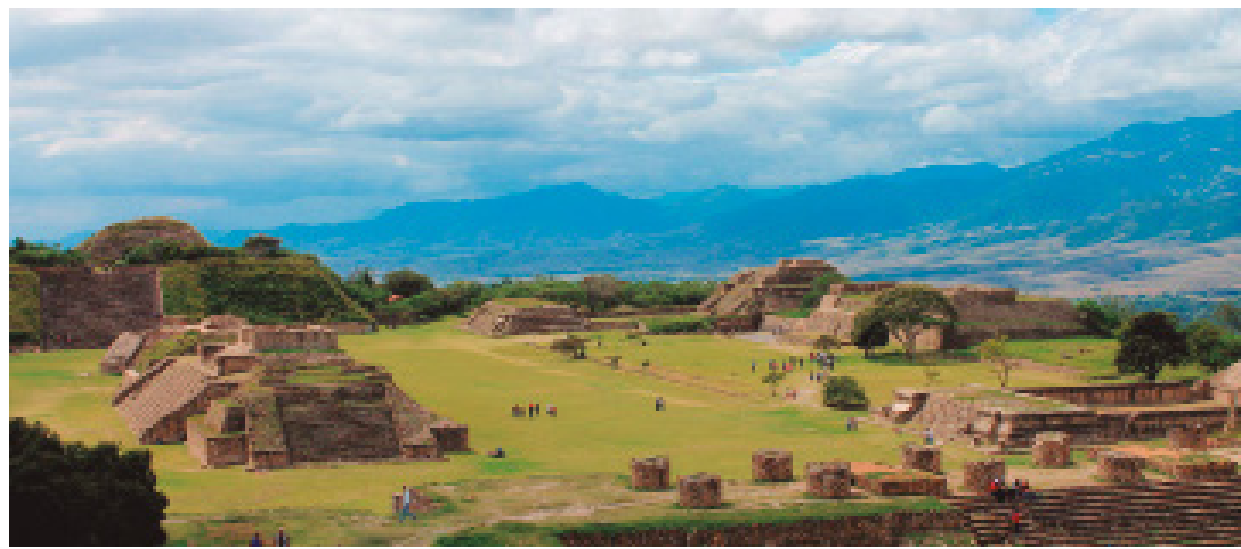

Figura 4. Monte Albán. Recuperado de https://www.hotelcasadesierrazul.com/Recorridos-Turisticos-Oaxaca.php

\section{Turismo}

En el 1950, luego de que México había participado en diversas conferencias internacionales cuyo tema principal eran la conservación, preservación y valoración de los monumentos, el turismo comenzó a tomar un relativo interés y protagonismo. Es por ello que crea: (a) la Sectur en 1989 y (b) los fondos mixtos de promoción turística. De los fondos mixtos existentes hasta el presente, está el destinado a las ciudades coloniales y sus centros históricos que se denomina: fondo mixto ciudades coloniales y que engloba 44 ciudades de las más de 100 que se asentaron durante lo que se denomina época colonial.

Finalmente, pese a todo ello, el abordaje sobre las dinámicas que enfrentan los centros históricos y el patrimonio cultural son escasas y cuando se abordan estos temas se hace de manera muy marginal, vinculándolos al desarrollo del turismo, que aparece como prioridad ante otros tipos del desarrollo de población. Pese a estas iniciativas y la implementación de herramientas para la gestión de los centros históricos, los resultados no han sido positivos en todos los casos, pues existen muchos factores que aún generan dificultades en el proceso de planeación y gestión (Sepúlveda, 2017).

\section{El estado de Oaxaca}

Oaxaca es uno de los 31 estados que conforman la república mexicana y está dividido en 570 municipios (el estado con mayor cantidad de municipios); cada uno es gobernado por su respectivo ayuntamiento. Oaxaca tiene una extensión de $91783 \mathrm{~km} 2$, lo que lo coloca en el lugar del quinto estado más grande de la república. Históricamente, en esta zona se manifestó la cultura zapoteca, que floreció en el área de Monte Albán a partir del año 900 a. C. y, más tarde, en el año 1300, la cultura mixteca (ver Figura 4). En el territorio se han registrado más de 4000 comunidades hablantes de 15 idiomas (entre chinanteco, cuicateco, huave, ixcateco, mazateco, mixteco, náhuatl, zapoteco, entre otros). De acuerdo con Barabas y Bartolomé, 1990: «En Oaxaca existen tantas Oaxacas como regiones o culturas estudiadas». A su vez, Oaxaca es una zona considerada con mayor «complejidad geológica», por lo cual está considerada como zona altamente sísmica.

En cuanto a la población, según el informe de los principales resultados de la encuesta intercensal 2015, Oaxaca contaba hasta ese año con un total de 3967889 habitantes (Instituto Nacional de Estadística y Geografía, 2015, p. 1), ocupando el noveno puesto de los estados más poblados del país. La actividad económica más practicada en el estado es la del sector terciario, específicamente actividades comerciales, en servicios de restaurante, hoteles y transporte. Sin embargo, durante los últimos años, los go- 
devenir Vol. 6, Nº12, JULIO-DICIEMBRE 2019, pP. 67-84 - Estudios I ISSN 2312-7562 | E-ISSN 2616-4949 UNIVERSIDAD NACIONAL DE INGENIERÍ, LIMA

doi: https://doi.org/10.21754/devenir.v6i12.744

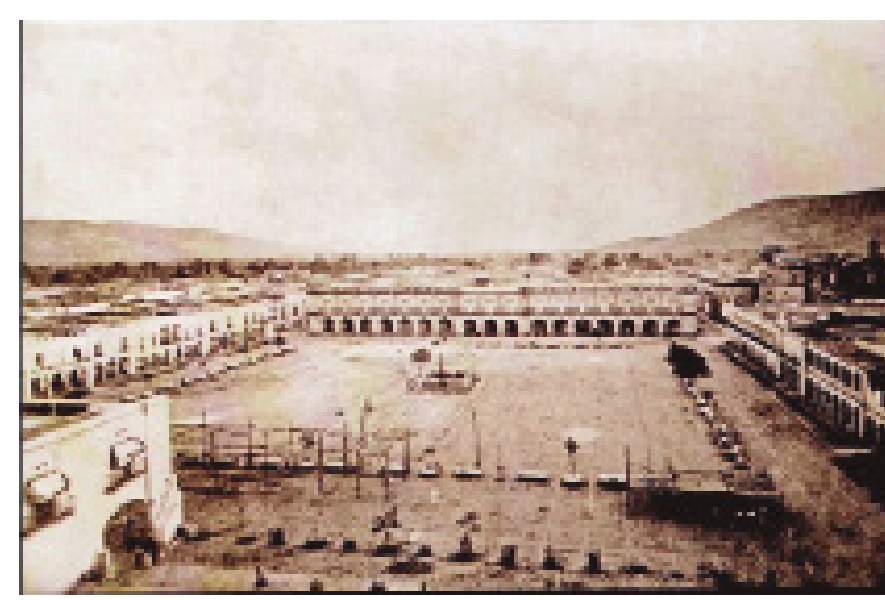

Figura 5. Plaza central de Oaxaca de Juárez, 1875. 475 años de la fundación de Oaxaca (Van Doesburg, 2007, p. 130).

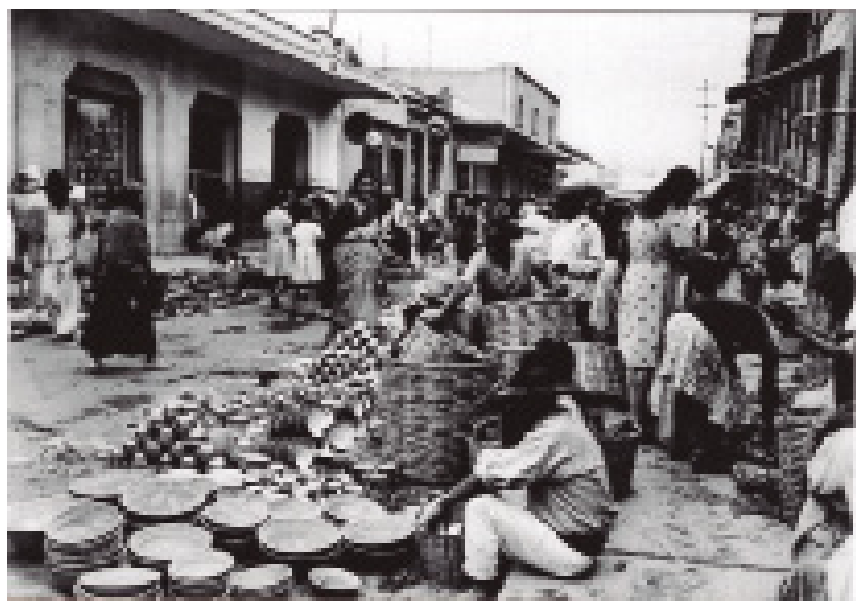

Figura 7. Mercado ambulante en el centro de la ciudad de Oaxaca. 475 años de la fundación de Oaxaca (Van Doesburg, 2007, p. 132).

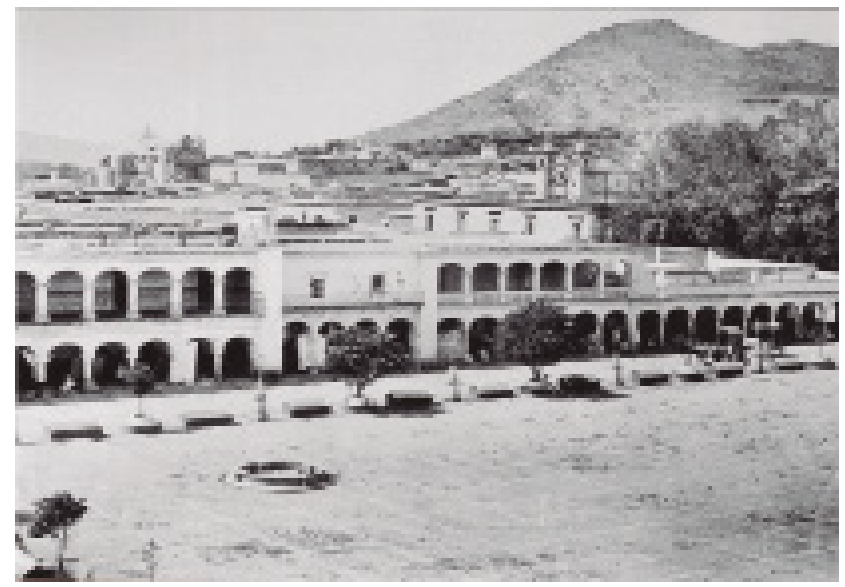

Figura 6. Poder político asentado en Oaxaca de Juárez, 1875. 475 años de la fundación de Oaxaca (Van Doesburg, 2007, p. 130).

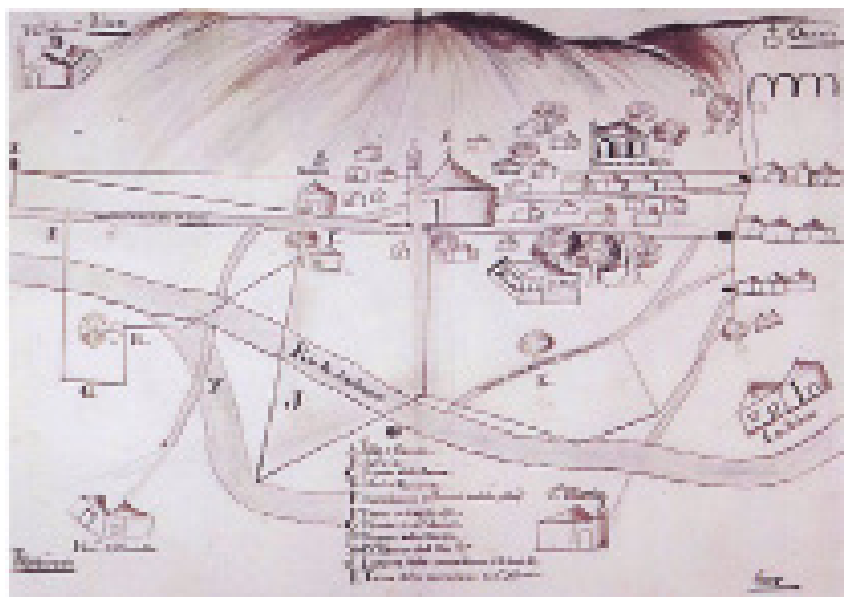

Figura 8. El Marquesado de la Villa de Oaxaca (se puede observar la traza a cordel delimitada por Alonso García Bravo. 475 años de la fundación de Oaxaca (Van Doesburg, 2007, p. 116).

IV. Ser ejemplo destacado de un tipo de obra de ingeniería, desarrollo de paisaje o arquitectónico que ilustra de manera significativa uno o varios períodos de la humanidad. (Unesco, 1987)

A partir de esta declaratoria fue necesaria la creación de organismos para su gestión, por lo que nació la Dirección General del Centro Histórico de Oaxaca de Juárez (en la actualidad Dirección de Centro Histórico y Patrimonio Edificado Respetuosa de la Ley), entidad pública, facultada para intervenir en la totalidad del territorio que abarca el ayuntamiento, no únicamente en el área delimitada por el polígono del Centro Histórico. Esta tiene como labor la administración y vigilancia en la defensa y conservación de edificios y monumentos históricos, artísticos y típicos de la zona. Por otro lado, las entidades privadas orientadas a la vigilancia de la gestión son diversas; sin embargo, destacan dos por su participación continua: el Consejo Consultivo Permanente del Centro Histórico y Pro-Oax (patronato para el mejoramiento del Centro Histórico; en la actualidad, Patronato Pro Conservación y Rescate del Patrimonio Cultural y Natural de Oaxaca), ambos orientados a la consulta y la defensa del patrimonio cultural en caso de obras nuevas que afecten a la sociedad y a las edificaciones declaradas como patrimonio. Una de las primeras acciones que se propuso la Dirección General del Centro Histórico fue la elaboración de un Plan Parcial de Conservación del 


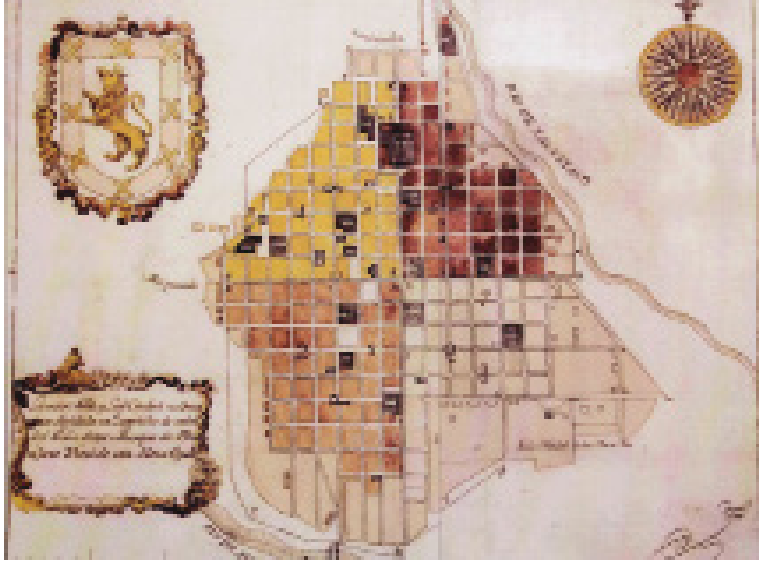

Figura 9. Plano de Oaxaca de 1795. 475 años de la fundación de Oaxaca (Van Doesburg, 2007, p. 139).

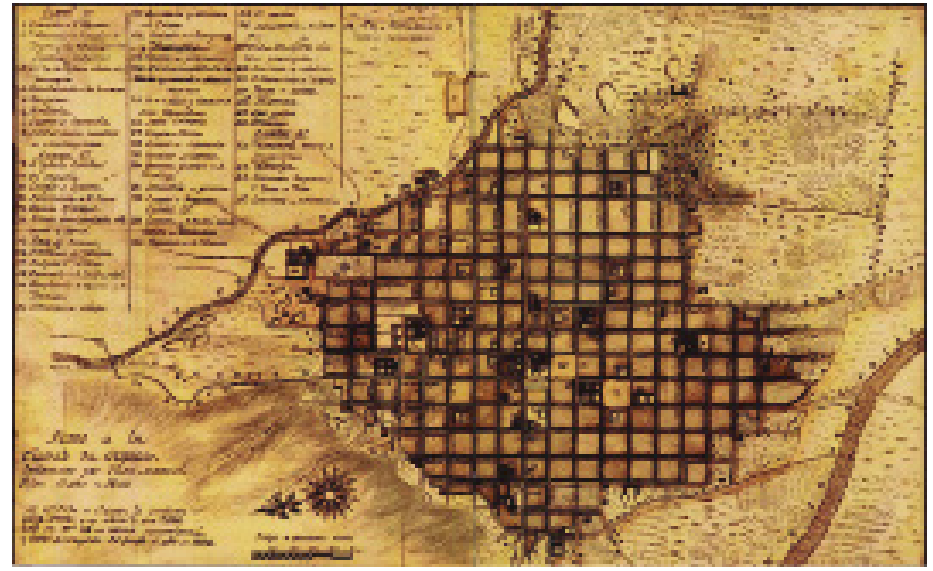

Figura 10. Plano de Oaxaca de 1803. 475 años de la fundación de Oaxaca (Van Doesburg, 2007, p. 134).

biernos estatales han tratado de sacar provecho al gran potencial turístico que ofrece el estado, contando con tres destinos que han puesto a Oaxaca en el mapa: la ciudad de Oaxaca de Juárez, Huatulco y Puerto Escondido.

\section{Oaxaca de Juárez y su Centro Histórico}

Oaxaca de Juárez es la capital del estado de Oaxaca y, a su vez, el municipio más poblado, con una cantidad total de 264251 habitantes según el Censo de Población y Vivienda del 2015 (Instituto Nacional de Estadística y Geografía, 2015, p. 3). La traza urbana de su Centro Histórico data de 1529 y fue delineada a cordel por Alonso García Bravo, quien buscó un terreno que estuviese protegido de los fuertes vientos, al sureste del Cerro del Fortín. Este trazo reticular conformó lo que sería la plaza central, en cuyos alrededores se asentaron los poderes políticos y religiosos de aquella época (ver Figuras 5 y 6). Posteriormente, durante los siglos XVII, XVIII y XIX, Oaxaca de Juárez se convirtió en una ciudad-mercado central, debido a un extenso sistema de mercados que se había estructurado de Guerrero a Guatemala, siendo Oaxaca de Juárez el punto central (ver Figuras 7, 8, 9 y 10).

Actualmente, el perímetro del Centro Histórico tiene una superficie de 544 ha, que representa el $31 \%$ de la ciudad de Oaxaca, dentro de la cual se encuentra una zona de monumentos históricos (252 ha), declarada por decreto presidencial en 1976 y de gran importancia porque fue el primer sitio del país en obtener dicho nombramiento.

El 11 de diciembre de 1987, la Unesco inscribió al Centro Histórico de Oaxaca de Juárez y a la zona arqueológica de Monte Albán como Patrimonio Mundial de la Humanidad. En ella se destaca que «el Centro Histórico de Oaxaca de Juárez muestra las principales órdenes religiosas que a partir del siglo XVI iniciaron la evangelización de México, por lo que este conjunto representa una realización arquitectónica y artística única, teniendo gran influencia en la región» (López, 2015, p. 4). Los criterios bajo los cuales se considera patrimonio al centro histórico de Oaxaca son los siguientes:

I. Representar una obra maestra de la creatividad humana.

II. Mostrar un intercambio importante de los valores humanos a lo largo del tiempo o un área cultural del mundo, en el desarrollo de la arquitectura o tecnología, artes monumentales, planeación o diseño urbano.

III. Representar un testimonio único o por lo menos excepcional de una tradición cultural o una civilización viviente o desaparecida. 
devenir Vol. 6, Nº12, JULIO-DICIEMBRE 2019, pP. 67-84 - Estudios I ISSN 2312-7562 | E-ISSN 2616-4949 UNIVERSIDAD NACIONAL DE INGENIERÍA, LIMA

doi: https://doi.org/10.21754/devenir.v6i12.744

Tabla 1. Leyes, planes y reglamentos a nivel municipal, estatal y federal de Oaxaca.

Federal

Estado de Oaxaca

\section{Municipio de Oaxaca de Juárez}

Constitución Política del Estado Libre y Soberano de Oaxaca
Reglamento de Bienes Patrimoniales Municipales
Constitución Política de los Estados Unidos Mexicanos
Ley de Protección a Monumentos Coloniales Artísticos e Históricos y poblaciones típicas del Estado de Oaxaca
Plan Parcial de Conservación del Centro Histórico de Oaxaca de Juárez
Ley Federal sobre Monumentosy Zonas Arqueológicas, Artísticas e Históricas
Ley de Desarrollo Urbano para el Estado de Oaxaca

Ley General de Asentamiento Humanos
Reglamento del Parcial de Conservación del Centro Histórico
Ley de Desarrollo Urbano Fede-

ral, 2019

Ley de Planeación
Reglamento del Instituto Municipal de Vivienda del

Municipio de Oaxaca de Juárez

Elaboración propia sobre la base de la bibliografía relacionada, 2019.

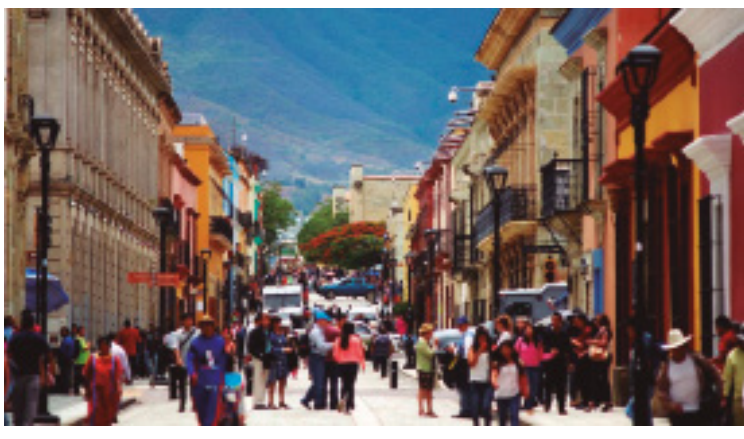

Figura 11. Centro Histórico de Oaxaca. Recuperado de https:// www.nvinoticias.com/nota/60695/el-centro-de-oaxaca-y-sus-tradicionales-barrios

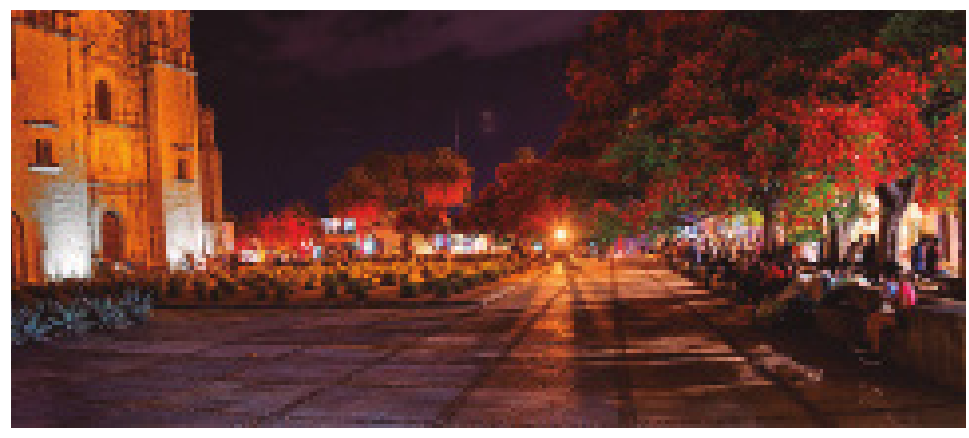

Figura 12. Centro Histórico de Oaxaca (convento Santo Domingo). Recupera-

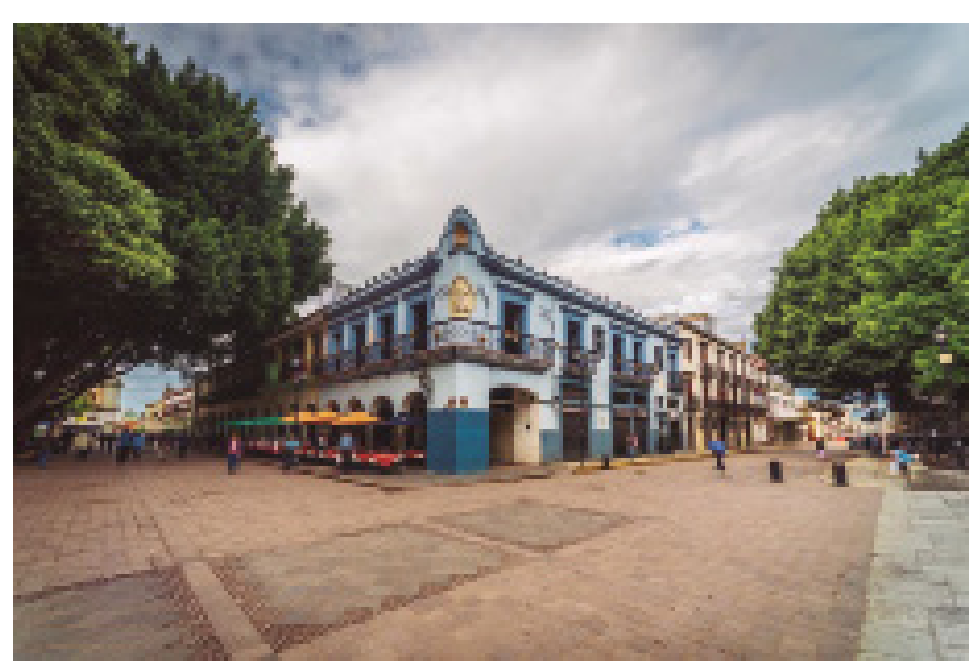

\section{do de https://jantusgaleria.wordpress.com/20170801_120957/}

Figura 13. Centro Histórico de Oaxaca. Página oficial en Facebook de la Coordinación de las Culturas, Turismo y Economía de Oaxaca. Recuperado de https://www facebook.com/401951076810320/ posts/736322150039876/ 

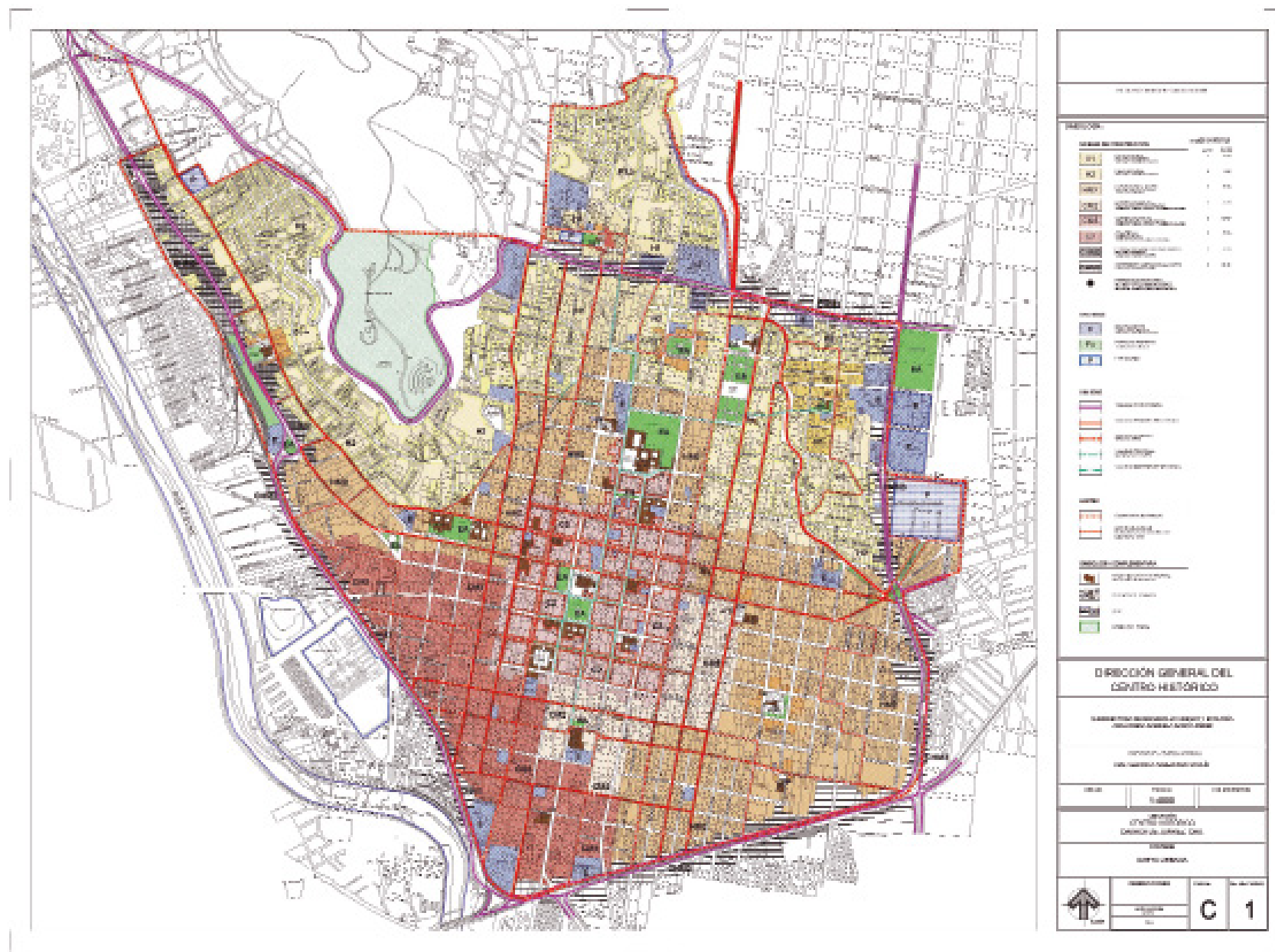

Centro Histórico de Oaxaca de Juárez (ver Tabla 1) y un reglamento general de la aplicación de este plan, que se aplicaría en el perímetro total de 544 ha (ver Figuras 11, 12, 13, y 14).

El área de estudio donde se aplicará la normatividad del Plan Parcial se estableció de acuerdo a bordes naturales como: El Cerro del Fortín, el Río Jalatlaco, y construidos como: La vía de ferrocarril y Periférico. Se han incorporado zonas como el Marquesado al poniente, Xochimilco al norte, la totalidad de Jalatlaco al oriente y Trinidad de la Huertas al sur, comprende una superficie de 544 Has [...] Dentro de esta área queda inscrita el área del Polígono del Decreto Federal del 19 Marzo de 1976. (Ayuntamiento de Oaxaca de Juárez, 2017, p. 3)

\section{Plan Parcial de Conservación 1997}

Este plan se usará como referencia para describir algunos datos puntuales que fueron tomados del área de actuación, en 1997. Asimismo, nos permitirá evaluarlo más adelante para confirmar si llegaron a funcionar y cuáles son los nuevos retos que se presentan en la actualidad. Cabe resaltar que uno de los objetivos principales del plan era el siguiente:

Mantener la función y el carácter del Centro Histórico como un Centro de ciudad dinámico y vivo, con la diversidad de actividades comerciales, turísticas, culturales, recreativas y sociales que hoy ofrece, además de los usos habitacionales que aseguren la permanencia de la población en beneficio de la vitalidad del mismo. (Ayuntamiento de Oaxaca de Juárez, 1997, p. 3).
Figura 14. Carta Urbana del Centro Histórico de Oaxaca. Dirección General del Centro Histórico, 2019. 
devenir Vol. 6, N¹2, JULIO - DICIEMBRE 2019, PP. 67-84 - EstudIOS I ISSN 2312-7562 | E-ISSN 2616-4949

UNIVERSIDAD NACIONAL DE INGENIERÍA, LIMA

doi: https://doi.org/10.21754/devenir.v6i12.744

Por lo tanto, el Plan Parcial de 1997 señalaba los siguientes puntos (Ayuntamiento de Oaxaca de Juárez, 1997):

Existía una disminución relativa poblacional por el crecimiento del comercio en Oaxaca de Juárez; sin embargo, la población del Centro Histórico se conservaba gracias a la existencia de los barrios tradicionales y de los usos mixtos que mezclan la habitación con actividades comerciales.

Para 1997, el Centro Histórico contaba con 10720 viviendas, de las cuales el 55 \% eran propias y el $45 \%$ eran rentadas. El número promedio de habitantes por vivienda era de 4,5. El nivel de hacinamiento era alto, al tomar como indicador las viviendas con un solo cuarto que alcanzan un $13 \%$. En general, se ubicaban en casas con arquitectura tradicional en deterioro (Ayuntamiento de Oaxaca de Juárez, 1997, p. 10).

La mayoría de las viviendas en este polígono contaban con todos los servicios, debido a la antigüedad de este espacio. Estas tenían un mejor servicio de drenaje a la calle, con el $92 \%$, en comparación con el $65 \%$ del resto del municipio, y el 98 \% contaban con energía eléctrica (Ayuntamiento de Oaxaca de Juárez, 1997, p. 11).

Para aquella época, el Centro Histórico concentraba el $44 \%$ de uso habitacional, $22 \%$ de uso comercial (referidos a comercio, mixto, hoteles, bodegas, industrias y talleres), un $9 \%$ en equipamiento (educativo, cultural, recreativo, salud, religioso, terminales de transporte, plazas y áreas verdes), $20 \%$ de vialidad, $3 \%$ de otros usos (estacionamientos y lotes baldíos) y un $2 \%$ de oficinas y bancos. Sin embargo, alrededor del zócalo (plaza) se concentraba el $50 \%$ de establecimientos comerciales, de manufactura y servicios de la ciudad (Ayuntamiento de Oaxaca de Juárez, 1997, p. 13).

Existían lotes baldíos en zonas norte y sur del centro, sin reglamentación del uso del suelo.

La actividad económica básica era el turismo, la cual registraba, desde 1990, una alarmante tendencia a decrecer. Según estadísticas de la Sectur, entre 1990 y 1994, la afluencia de visitantes descendió un 21,6 \% y la ocupación hotelera disminuyó de 53,10 \% a 43,10 \%. Es por ello que, a partir de ese momento, se trató de convertir al centro histórico en un nodo turístico, lo cual conllevó los problemas que veremos más adelante.

El costo de suelo en el centro histórico variaba entre los 600 y 4850 pesos mexicanos por metro cuadrado (aproximadamente 100 y 820 soles), siendo el precio más alto el de la zona alrededor del zócalo (plaza), con un costo aproximado de entre 2500 y 4850 pesos mexicanos (aproximadamente 420 y 820 soles) (Ayuntamiento de Oaxaca de Juárez, 1997, p. 14).

La revisión de los inmuebles inventariados por el INAH arrojaba un patrimonio edificado integrado de 1483 inmuebles. El $11 \%$ estaban en ruinas, otro $11 \%$ estaban subdivididos, $26 \%$ con alteraciones muy graves y, según la afirmación del plan, existía un $62 \%$ en buen estado (Ayuntamiento de Oaxaca de Juárez, 1997, p. 18).

Falta de estacionamientos y de orden vial como foco de congestionamiento.

Para enfrentar estos problemas se plantearon diversas estrategias para el ordenamiento, como conservar el uso habitacional en los barrios tradicionales, a través de la reglamentación del uso del suelo y de programas de mejoramiento de barrios, colonias populares y vecindades (con acciones dirigidas a la conservación de la arquitectura popular, a controlar la señalización comercial y a ambientar las calles que requieran arborización y mobiliario urbano); se promovió la construcción de vivienda nueva en los lotes baldíos (se proponía la utilización de 13 baldíos existentes al sur de Xochimilco, con una superficie aproximada de $15270 \mathrm{~m}^{2}$ ); y se definió el uso comercial y mixto con el habitacional, de acuerdo con el carácter y potencial de las diferentes zonas del centro, para frenar la expulsión de población y el deterioro de los edificios de vivienda. Además, se planteó la construcción de estacionamientos nuevos en torno a los pares viales perimetrales al 


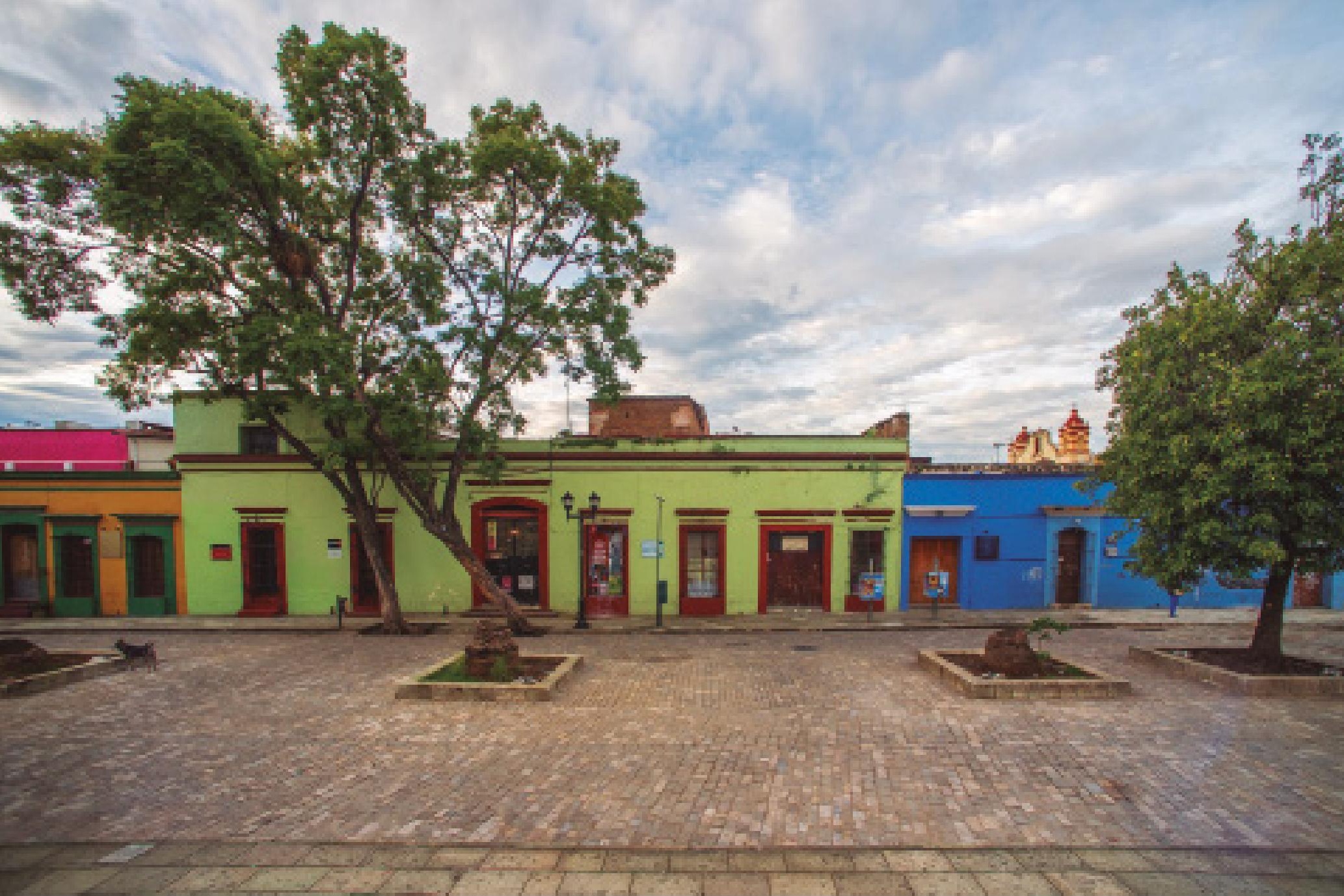

Centro-Zócalo y la extensión del programa de estacionamiento de 1 hora a 2 horas, entre otras medidas. Asimismo, se proyectó una actualización de los inmuebles catalogados como patrimonio por el INAH, así como la restauración no solo de monumentos históricos sino también de viviendas tradicionales como parte de la mejora del perfil del centro histórico, y se llevó a cabo una gran difusión del plan a la ciudadanía (ver Figuras 15 y 16).

Por el lado del financiamiento, el centro histórico de Oaxaca de Juárez se acoge al Programa de 100 Ciudades Medias (programa federal), el cual plantea, dentro de su Programa de Renovación Urbana de los Centros de las Ciudades, el apoyo normativo, financiero y participante a nivel federal para realizar las acciones que se derivan del plan parcial. «Propone el financiamiento de las acciones mediante aportación conjunta de la federación, el estado, el municipio, recursos privados y crediticios, de acuerdo al tipo de acción y señala la participación adicional de organismos como: Banobras, Nafin, CFE, Telmex, para apoyos alternativos de crédito y financiamiento» (Ayuntamiento de Oaxaca de Juárez, 1997, p. 33). Asimismo, se proponen estímulos fiscales para la mayor inversión de las empresas, como exenciones fiscales por obras de restauración, exenciones fiscales temporales a comerciantes que participen en obras de rescate, transferencia de potencialidad (con permisos adicionales en el Corredor Urbano del Periférico y otras zonas de la ciudad que generen recursos para canalizarlos al Centro Histórico), y créditos internacionales y nacionales para invertirlos en el Centro Histórico.

Por esta misma línea se reciben apoyos de la Secretaría de Cultura con el programa Apoyo a las Ciudades Mexicanas Patrimonio Mundial (ACMPM), que es un programa federal a cargo de la Dirección General de Sitios y Monumentos del Patrimonio Cultural de la Secretaría de Cultura que contribuye a conservar el legado y monumentos de sitios de una gran riqueza natural y cultural que han estado declarados por la Unesco como ciudades Patrimonio Mundial; el Programa de Apoyo a la Infraestructura Cultural de los Estados
Figura 15. Casas del Centro Histórico de Oaxaca. Página oficial en Facebook de la Coordinación de las Culturas, Turismo y Economía de Oaxaca. Recuperado de https://www. facebook.com/401951076810320/ posts/736322150039876/

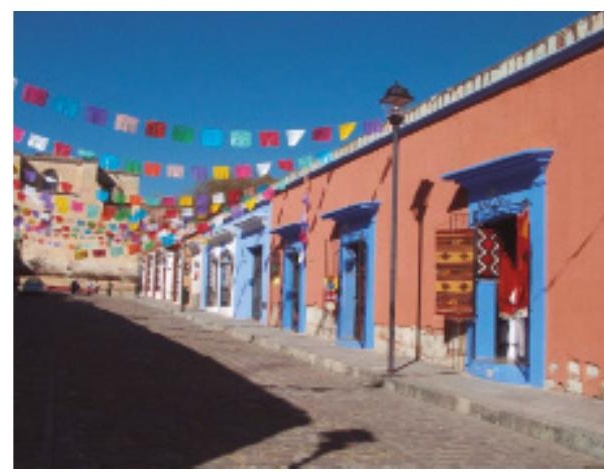

Figura 16. Casas del Centro Histórico de Oaxaca. Archivo de Aciel Sánchez, 2014. 
devenir Vol. 6, N¹2, JULIO - DICIEMBRE 2019, PP. 67-84 - EstudIOS I ISSN 2312-7562 | E-ISSN 2616-4949

UNIVERSIDAD NACIONAL DE INGENIERÍA, LIMA

doi: https://doi.org/10.21754/devenir.v6i12.744

(Paice) a cargo de la Dirección General de Vinculación General (DGVC), que en la actualidad está llevando a cabo la rehabilitación y equipamiento del Museo Infantil de Oaxaca; y el Programa de Apoyo a las Culturas Municipales y Comunitarias (PACMYC).

Este plan, aprobado en sesiones ordinarias por el cabildo, entró en vigor en noviembre de 1997, pero no fue sino hasta el 15 de diciembre de 1998 que la Gaceta Municipal se encargó de difundirlo para conocimiento de la ciudadanía.

Este instrumento no ha tenido una actualización ni un seguimiento para constatar las mejoras a lo largo de veinte años. Como lo señalaba el urbanista mexicano Xavier Hernández en la revista Gaceta:

Tiene que revisarse y actualizarse, y para estas fechas ya tendría que haberse hecho; ver cómo les opera y que los diferentes grupos se pongan de acuerdo para determinar qué ajustes se necesitan y que responda así a las necesidades de hoy. (La Gaceta, 2004, p. 4)

Finalmente, la manera como fueron resueltas algunas de estas estrategias llamó la atención. Un ejemplo de ello fue la creación del estacionamiento del Cerro del Fortín. El proyecto fue ubicado en el Parque de la Amistad de la colonia Guelaguetza, ocasionando la destrucción del espacio público. Ello viola el artículo 10 del Reglamento del Plan Parcial del Centro Histórico, en donde «se prohíbe la alteración y transformación de espacios abiertos, inmuebles patrimoniales, vialidades, y entorno natural ya que conforma la importancia, el valor y el carácter del Centro Histórico» (López, 2015, p. 13).

\section{Nuevos retos de la actualidad}

En el 2010, según el inventario de vivienda (INV), se registró una disminución de la cifra de habitantes del Centro Histórico de Oaxaca de Juárez: pasaron de 49000 a 31263 habitantes en un período de 13 años. Es decir, más de 1300 habitantes se retiraban del Centro anualmente (López, 2015, p. 6). Una de las principales razones fue la demanda de usos de suelos comerciales destinados al turismo. Hoy, en el año 2019, se presenta un reto mayor con la proliferación del comercio informal. Según el observatorio económico México, ¿Cómo Vamos? del 2015, el 74,6 \% de la economía oaxaqueña se encuentra en el sector informal, lo que lo convierte en la entidad con mayor tasa de informalidad a nivel nacional. Es por ello que Oaxaca sigue siendo un estado con muy baja productividad. La gran cantidad de comercio informal alrededor del Centro Histórico de Oaxaca de Juárez se ha incrementado estos últimos años. Este fenómeno ha ocasionado un gran impacto en la microempresa que ha llevado a la Alianza Empresarial y Comercial de Oaxaca AC (AECO) a dimitir al pago de los impuestos hasta que se garantice que el ambulantaje sea un problema resuelto, ya que sus ventas bajaron al $60 \%$. El autor René Coulomb considera que el desarrollo económico de los centros históricos debe «llevarse sobre la base de la heterogeneidad de los usos de suelo, y no únicamente sobre la multiplicación de usos al turismo y a la actividad comercial» (Coulomb, 2006, p. 38).

En cuanto al tema de vivienda, en el 2017, Oaxaca fue uno de los estados que recibió menos apoyos de la Comisión Nacional de Vivienda (Conavi): el estado logró únicamente 1100 subsidios de los 101697 subsidios totales repartidos, lo que representa el 1,08 $\%$ del total nacional. Por el monto económico, los recursos fueron 35,5 millones de pesos, el 0,76 \% del total, es decir, 4616 millones de pesos (Avendaño, 2018). Asimismo, según los datos de la Protección Civil Municipal del municipio de Oaxaca de Juárez, más de 80 viviendas del centro histórico catalogadas se encontraban en mal estado, de las cuales el $50 \%$ representan un peligro latente para los ciudadanos. Según afirman, la gran cantidad de abandonos se debe al complicado trámite burocrático que exigen las autoridades municipales, estatales y federales para una rehabilitación (Torres, 2019).

Por otro lado, las fundaciones y organizaciones de la sociedad civil han comenzado a tener otro papel protagónico. La Fundación Harp Helú de Oaxaca (Fahho) es muestra 


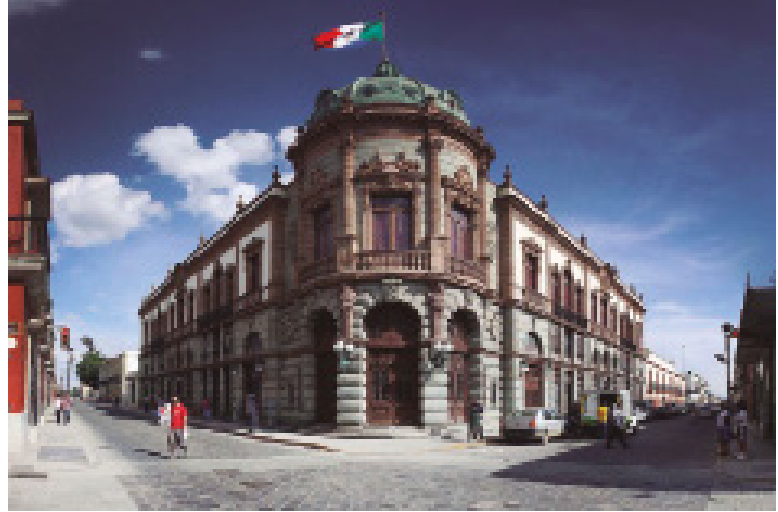

Figura 17. Teatro Macedonio Alcalá. Recuperado de http:// www.epdlp.com/edificio.php?id=5973

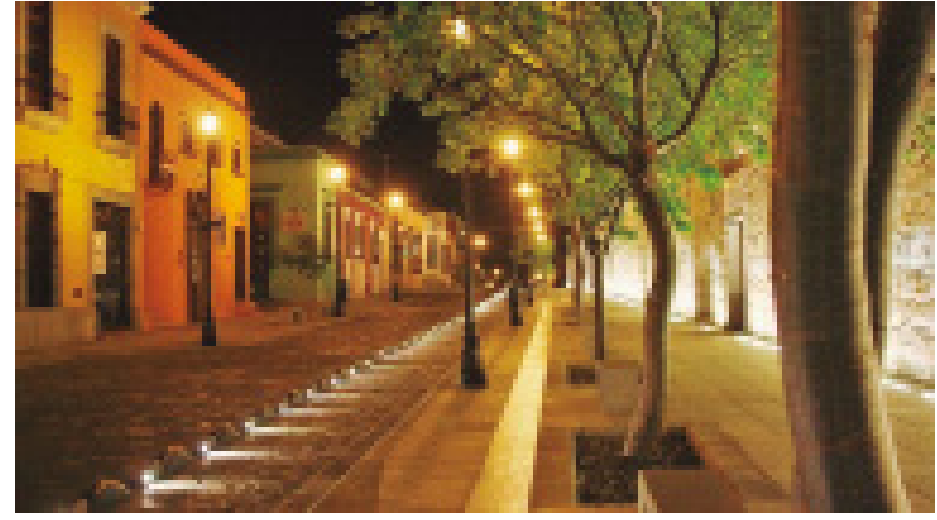

Figura 18. Calles del Centro Histórico de Oaxaca. Recuperado de http:// www.epdlp.com/edificio.php?id=5973

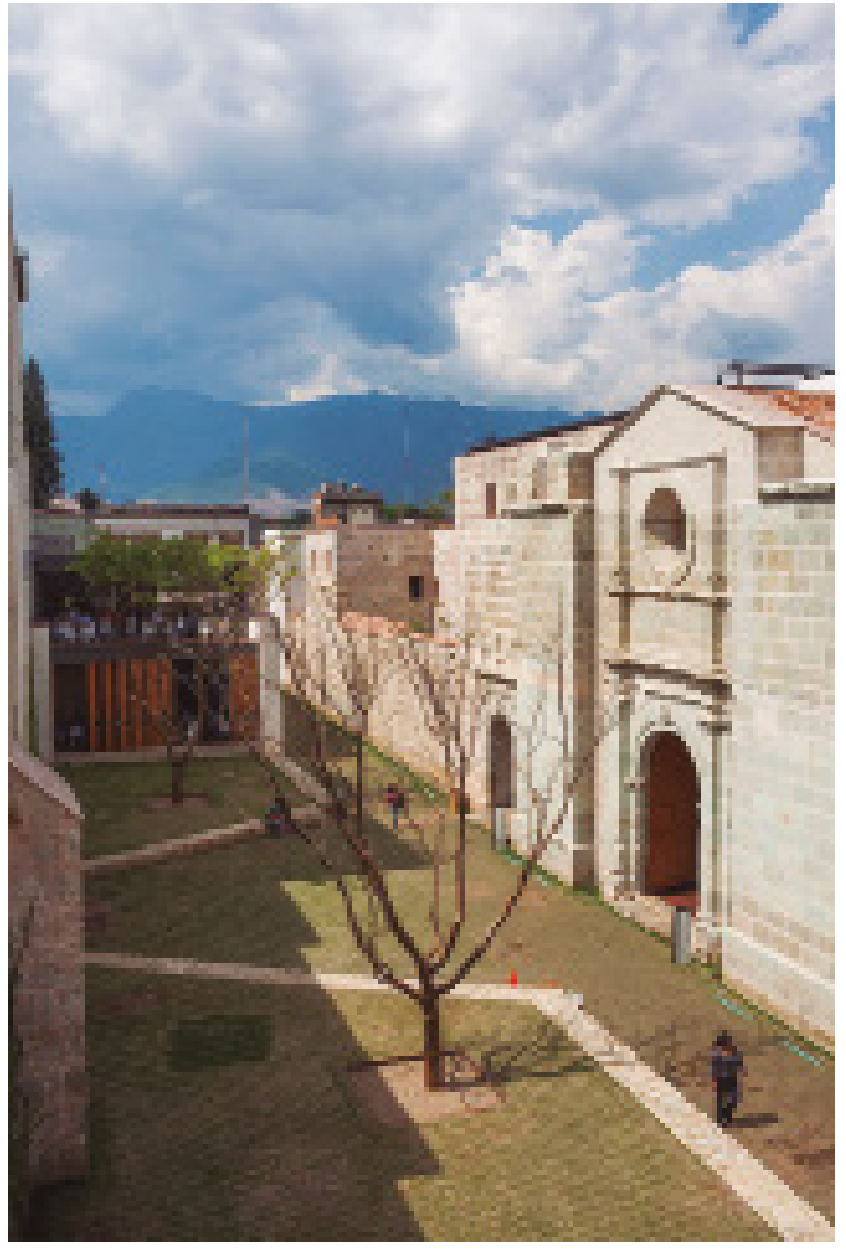

Figura 19. Patio del Centro Cultural San Pablo. A rchivo de la fotógrafa Sandra Pérez Nieto. Recuperado de https://pereznieto.com/project/centro-academico-y-cultural-san-pablo/

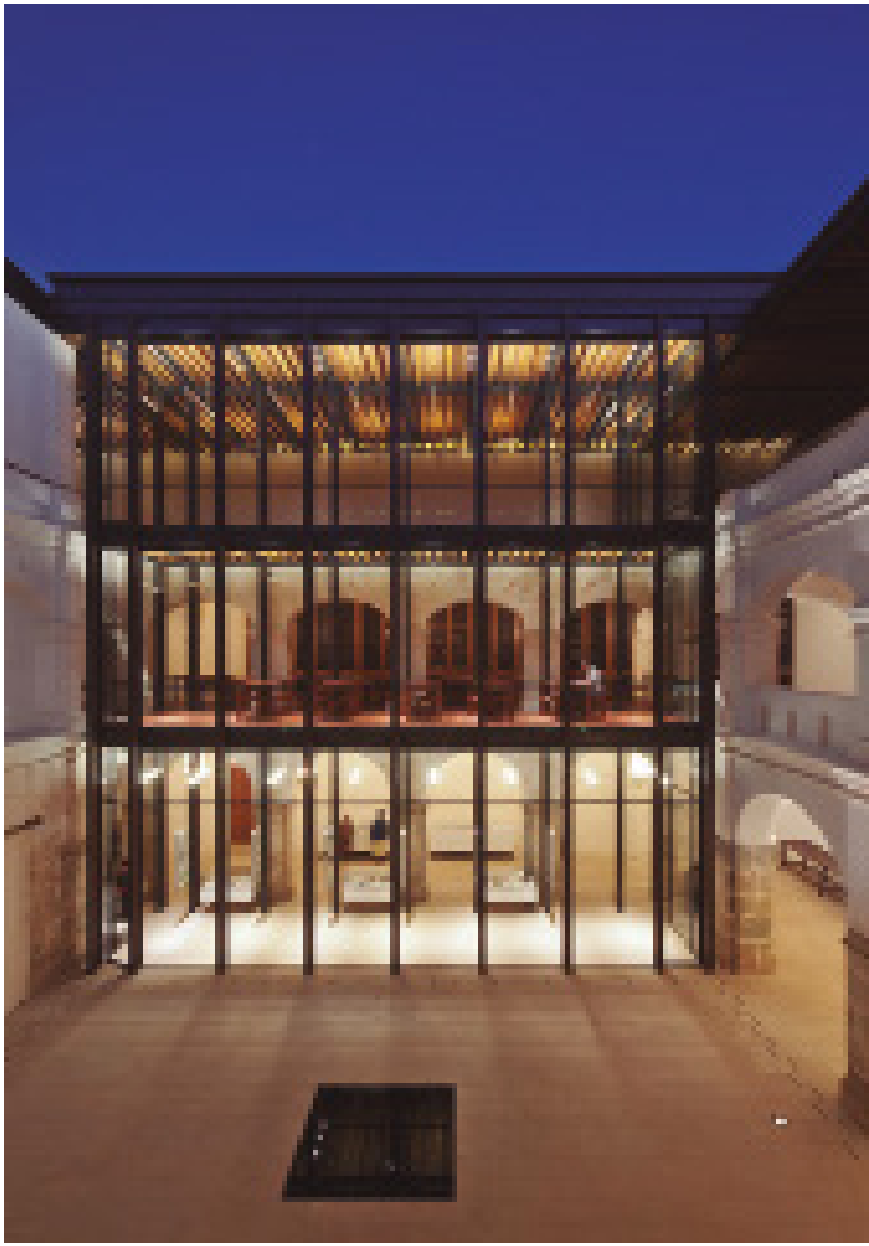

Figura 20. Inserción de arquitectura contemporánea en el Centro Cultural San Pablo. Archivo de la fotógrafa Sandra Pérez Nieto. Recuperado de https://pereznieto.com/project/centro-academico-y-cultural-san-pablo/ 


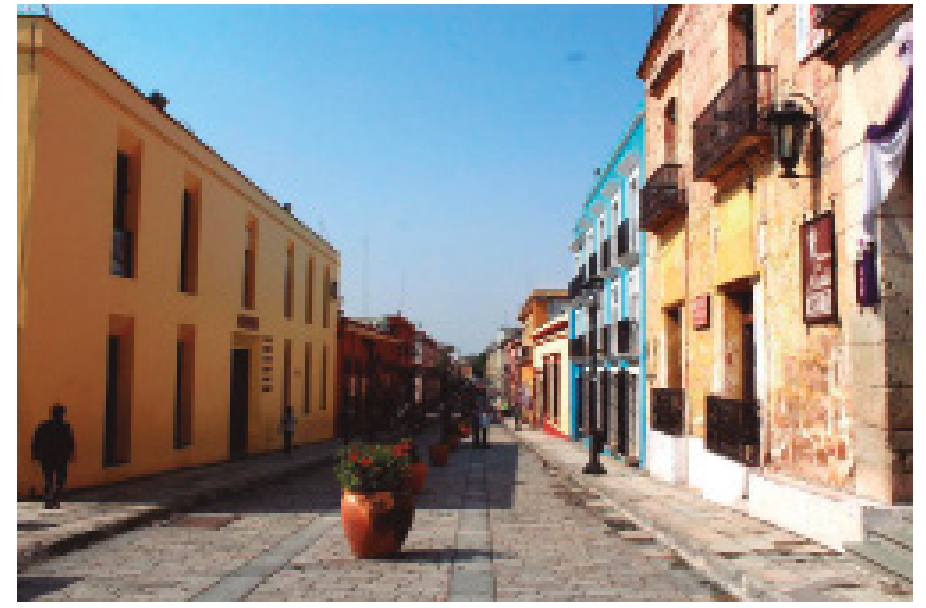

Figura 21. Calle de Centro Histórico. Recuperado de http://sucedioenoaxaca.com/2017/05/08/oaxaca-de-juarez-rumbo-a-su-30-aniversario-como-patrimonio-cultural-de-la-humanidad/

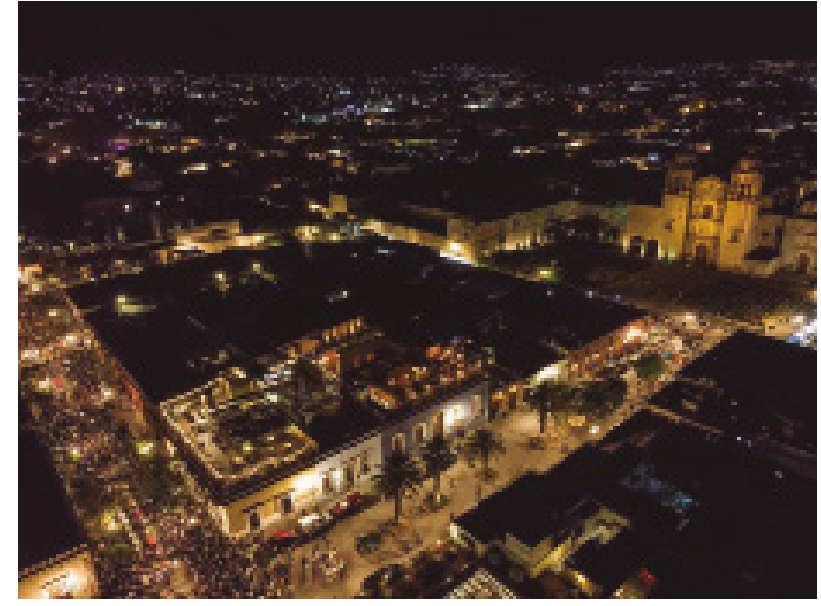

Figura 22. Calles del Centro Histórico en la celebración del Día de los Muertos. Página oficial en Facebook de la Coordinación de las Culturas, Turismo y Economía de Oaxaca. Recuperado de https://www.facebook.com/401951076810320/posts/736322150039876/

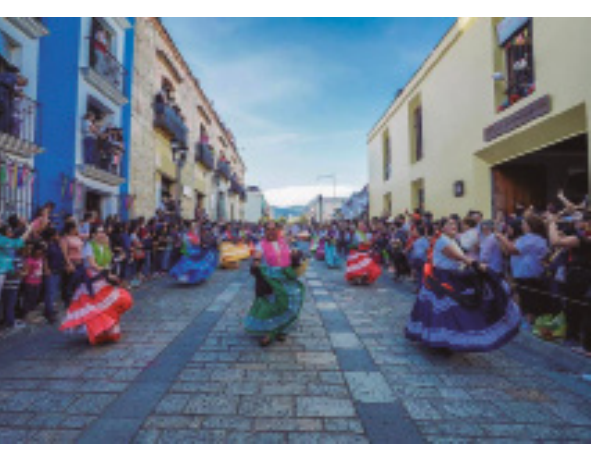

Figura 23. Calles del Centro Histórico en la celebración de la festividad de la Guelaguetza. Página oficial en Facebook de la Coordinación de las Culturas, Turismo y Economía de Oaxaca. Recuperado de https://www. facebook.com/401951076810320/ posts/736322150039876/ de ello con proyectos no solo de financiamiento sino también con la creación de programas para el desarrollo de la cultura en Oaxaca. Como ejemplo, la Fahho dispuso la creación del Centro Académico y Cultural San Pablo, que ocupa el ex convento de Santo Domingo de Soriano para sus actividades. La fundación adquirió el predio y puso en marcha la rehabilitación y rescate de este inmueble histórico. Este es uno de sus proyectos más ambiciosos y lleva invertidos en él 180 millones de pesos. La cooperación española también ha sido bastante activa en Oaxaca. Hacia el año 2010, en el marco de la XIII Subcomisión Mixta de Cooperación Técnica y Científica México-España, se firmó el convenio para el establecimiento y funcionamiento de la Escuela Taller de Oaxaca, en el Centro Cultural Santo Domingo. Asimismo, la Fundación Telmex ha fomentado la oferta con su patrocinio a la temporada de la Guelaguetza. El presupuesto que esta fundación invierte en dicho evento cultural ha llegado a alcanzar los cinco millones de pesos (Gobierno del Estado de Oaxaca, 2011, p. 99) (ver figuras 17, 18, 19, 20, 21, 22 y 23).

\section{Comentarios finales}

1. Los Estados Unidos Mexicanos es una república federal dividida en estados y municipios independientes; esto permite que las autoridades competentes tengan un análisis urbano más detallado sobre la ciudad a través de la realización de cartas urbanas, planes municipales, reglamentos, entre otros, y que el crecimiento de sus ciudades ocurra de una manera más ordenada. Sin embargo, son las coordinaciones y los acuerdos entre el estado, el municipio y el gobierno federal lo que retrasa las viabilidades de muchos proyectos. Si bien existen secretarías como Sedesol, que tratan de generar una sinergia entre estos tres niveles, aún la descoordinación es evidente.

2. Tomando como base la bibliografía consultada, podemos concluir que los organismos federales de mayor importancia para la conservación del Centro Histórico, a lo largo de este tiempo, han sido el INAH, la Sectur y el Fonca. Sin embargo, en estos últimos años la Sedesol, desde su Dirección General de Desarrollo Urbano, ha tomado un protagonismo importante debido a sus programas de ayuda para mejorar la formulación y evaluación de los planes de manejos de los centros históricos y a programas de apoyo financiero (Hábitat) que destinan fondos para las mejoras de los centros históricos. Asimismo, la Sectur ha cobrado otro valor importante, debido a los programas y distintos tipos de apoyos financieros para proyectos referidos al 
desarrollo turístico de los centros históricos de las ciudades mexicanas. Esto es parte del reflejo del Plan Nacional de Desarrollo (2013-2018) del gobierno de Enrique Peña Nieto, donde se considera al sector turismo como un eje principal (México Próspero) para el desarrollo económico del país, por lo que a nivel estatal y municipal también se plantea esta política. Municipios como el de Oaxaca de Juárez han concentrado su desarrollo sobre la base de una perspectiva turística limitada, ocasionando una fuerte y peligrosa tendencia a cambiar el uso de suelo de vivienda a comercial que satisfaga al turismo, como se vio reflejado en el 2010 con una reducción de más de 17737 personas en el Centro Histórico de Oaxaca, en un lapso de 13 años. Para Álvarez Mora, estos espacios (centros históricos) se han manejado como algo independiente al resto de la ciudad, dado que son vistos como una zona cultural, y fuera de ella no se plantean espacios culturales, trayendo como consecuencia una saturación y desgaste de los sitios históricos (Mora, 2006).

3. Si bien el Plan de Conservación del Centro Histórico de Oaxaca de Juárez de 1997 recogió buenas estrategias para enfrentar algunos problemas de la época, estas no fueron resueltas a cabalidad por la falta de especificidad y falta de la participación consensuada en él, pese a que fue planteado "como un instrumento participativo y acordado» (Ayuntamiento de Oaxaca de Juárez, 1997). La nueva problemática de la actualidad (2019) exige no solo una actualización del plan parcial sino mayor especificidad y una participación más activa de las distintas Direcciones (Desarrollo Urbano, Turismo, Vivienda, entre otras) tanto del municipio, del estado e incluso a nivel federal por ser considerado como Patrimonio de la Humanidad. Parte de esta problemática surge como consecuencia de colocar la actividad turística como eje principal de su economía, descuidando temas de inversión para la obra pública, infraestructura y servicios para los habitantes que viven tanto dentro como fuera del Centro Histórico. El turismo debe ser considerado como una empresa económica complementaria, no prioritaria, y es urgente dejar de tenerlo presente como determinante del desarrollo cultural de los pueblos como lo afirma Carlos Lira Vásquez, doctor de historia urbana de la Universidad Autónoma Metropolitana Azcapotzalco, en su investigación El discurso patrimonial: una coartada para frenar el desarrollo de la ciudad de Oaxaca.

4. Por otro lado, la economía informal no es un fenómeno nuevo, sino que ha sido una constante en la economía mexicana. Sin embargo, la situación se ha agudizado en mayor grado en el Centro Histórico de Oaxaca en la actualidad (2019). A pesar de que existe un reglamento para el comercio en la vía pública, este no se aplica ni es observable de manera general, permitiendo un descontrol y una total libertad para que los comerciantes ejerzan su actividad. Por ello, es de suma urgencia una reforma en la aplicación de su normativa comercial y que forme parte de la actualización del plan parcial para que se contemple el ordenamiento del Centro Histórico de Oaxaca, puesto que no solo la actividad comercial está alejando a los residentes, sino que ahora los comercios informales están alejando a los comercios formales que pagan impuestos del Centro Histórico.

5. Por otro lado, se encuentran los nuevos actores como la fundación Harp Helú de Oaxaca, que se ha convertido en el principal organismo del sector privado de apoyo cultural al Centro Histórico de Oaxaca de Juárez. Esta entidad se ha erigido como la más fuerte aliada de la Secretaría de Cultura, ya que genera condiciones favorables para el desarrollo de las culturas populares e indígenas, así como para el fomento de la creación y consumo artístico y cultural. Esta entidad, así como las distintas fundaciones y sociedades civiles deben ser consideradas como piezas claves no solo para la inversión de proyectos culturales sino como agentes activos de participación en las propuestas para el desarrollo de un plan actualizado o instrumento que conlleve la mejora del Centro Histórico de Oaxaca de Juárez y trabajar de la mano con la dirección del mismo. 
devenir Vol. 6, N¹2, JULIO - DICIEMBRE 2019, PP. 67-84 - EstudIOS I ISSN 2312-7562 | E-ISSN 2616-4949

UNIVERSIDAD NACIONAL DE INGENIERÍA, LIMA

doi: https://doi.org/10.21754/devenir.v6i12.744

\section{Referencias}

Alarcón, P. G. (2018). Zona de monumentos históricos Santiago de Querétaro. Devenir, 5(9), 117-136.

Avendaño, A. P. (7 de junio del 2018). Subsidios para viviendas no aterrizan en Oaxaca. El Imparcial (Oaxaca). Recuperado de http://imparcial.oaxaca.mx/oaxaca/173686/subsidios-para-vivienda-no-aterrizan

Ayuntamiento de Oaxaca de Juárez. (1997). Plan Parcial de Conservación del Centro Histórico de Oaxaca.

Ayuntamiento de Oaxaca de Juárez. (2017). Reglamento General de Aplicación del Plan Parcial del Centro Histórico de Oaxaca de Juárez.

Cámara de Diputados del Honorable Congreso de la Unión. (2018). LXIV-Legislatura. Recuperado de http://archivos.diputados.gob.mx/Centros_Estudio/Cesop/Comisiones/2_cultura.htm

Carrión, F. (2000). Desarrollo cultural y gestión en centros históricos, Quito: Facultad Latinoamericana de Ciencias Sociales (FLACSO).Comisión Económica para América Latina y el Caribe. (2008). Programa Hábitat de la Secretaria de Desarrollo Social (SEDESOL). Recuperado de http//www.cepal.org/noticias/paginas/4/39104/CUADROS_Programa_Habitat.pdf

Coulomb, R. (2006). Sostenibilidad social en los centros históricos. La Habana: Ediciones Boloña.

Frutos, E. A. (2008). Alternativas de financiamiento en centros históricos de México. Quivera, 10(2), 1-17.

Gobierno del Estado de Oaxaca. (2011). Programa Sectorial de Cultura 2011-2016. Diversidad Cultural y Patrimonio para el Desarrollo.

Hayakawa, J. (2015). Gestión del patrimonio cultural y centros históricos latinoamericanos. Lima: Universidad Nacional de Ingeniería.

Instituto Nacional de Estadística y Geografía. (2015). Principales resultados de la Encuesta Intercensal 2015. Oaxaca.

Instituto Nacional de Estadística y Geografía. (2017). Anuario estadístico y geográfico de los Estados Unidos Mexicanos.

Instituto Nacional de Estadística y Geografía. (2018). Principales resultados de la Encuesta Intercensal 2018 de Los Estados Unidos Mexicanos.

López, Y. R. (2015). La transformación urbana a partir de la declaratoria patrimonial. Universidad Nacional Autónoma de México.

Mora, A. A. (2006). El mito del centro histórico: El espacio del prestigio y la desigualdad. Puebla: Universidad Iberoamericana Puebla.

Portal Iberoamericano de Gestión Cultural. (s. f.). Asociación Nacional de Ciudades Mexicanas del Patrimonio Mundial (ANCMPM). Recuperado de http://www.gestioncultural.org/recursos_ culturales.php?id_enlaces $=304605$

Secretaría de Gobernación. (2011). Acuerdo por el que Modifican las Reglas de Operación del Programa Hábitat para el Ejercicio Fiscal. Recuperado de http//dof.gob.mx/nota_detalle.php?codigo $=5173562 \&$ fecha $=31 / 12 / 2010$

Sepúlveda, D. S. (2017, enero). Estado del arte sobre centros históricos de México. Red Temática Conacyt: Centros históricos de Ciudades Mexicanas. Recuperado de http://www.red-centros-hist.unam.mx/assets/anexo-1-estado-del-arte-ch-(1).pdf

Torres, H. (2019, 1 de junio). Centro Histórico de Oaxaca se encuentra en riesgo. El Imparcial (Oaxaca). Recuperado de http://imparcialoaxaca.mx/la-capital/314641/centro-historico-de-oaxaca-se-encuentra-en-riesgo/

Unesco. (1987). Criterios de selección. Recuperado de https://whc.unesco.org/es/list/415

Var Doesburg, S. (2007). 475 años de la fundación de Oaxaca. Oaxaca: Ayuntamiento de la ciudad de Oaxaca. 